\title{
¿Héroes o villanos? Azúcares en la salud y la enfermedad
}

\author{
Ángela Ávila Fernández, Sandra del Moral y María Elena Ortiz-Soto
}

\begin{abstract}
Resumen
Cuando escuchamos hablar de azúcares, generalmente los asociamos con postres y golosinas, y en un segundo plano con enfermedades como caries, diabetes y obesidad. En redes sociales, blogs y revistas, se refuerza frecuentemente la idea de que los azúcares son nocivos para nuestra salud y por tanto hay que evitarlos. Así pues, el carácter "virtuoso" de los azúcares es inseparable en el imaginario colectivo de su contraparte "malvada". Además de los relacionados con la dieta, existen otros azúcares con gran diversidad funcional, cuyo papel es fundamental en varios eventos fisiológicos y patológicos. Aquí te explicamos algunos de los asombrosos procesos que son dirigidos, regulados o acompañados por estos azúcares, y analizamos sus efectos en la salud y la enfermedad.
\end{abstract}

Palabras clave: azúcares, glicoconjugados, infección, interacciones humano-patógeno, prebióticos.

\section{Heroes or VILLAINS? Sugars IN HEALTH AND diseASE}

\begin{abstract}
Whenever we hear the world sugar, sweets and desserts come to our minds, followed by thoughts of diseases such as cavities, diabetes and obesity. Information in social networks, blogs, and magazines often reinforces the misconception that sugars are always unhealthy and should therefore be avoided by all means. The virtuous attributes of sugars are thus permanently entangled with its evil counterpart. Sugars are molecules of great structural and functional diversity, which makes them essential in various physiological and pathological events, beyond their dietary-related role. Here we describe some amazing processes in which sugars are instrumental, and we analyze their effects on health and disease.
\end{abstract}

Keywords: sugars, glycoconjugates, infection, human-pathogen interaction, prebiotics.

Recepción: 12/09/2020. Aprobación: 19/01/2021. Dol: http://doi.org/10.22201/cuaieed.16076079e.2021.22.2.5 


\section{Ángela Ávila Fernández}

angela.avila@ujat.mx

Doctora en Ciencias Bioquímicas por el Instituto de Biotecnología de la unam. Profesora Investigadora de Tiempo Completo en la División Académica de Ciencias de la Salud de la Universidad Juárez Autónoma de Tabasco (UjaT) desde 2012. Investigadora Nacional Nivel I. Coordinadora del Doctorado en Ciencias Biomédicas de la ujat desde 2015. Directora de tesis de licenciatura, maestría y doctorado. Su línea de investigación está enfocada en comprender cómo las bifidobacterias metabolizan diferentes azúcares prebióticas para utilizar esta información en el desarrollo de nuevos y mejores simbióticos.

\section{Sandra del Moral}

sandra.dv@veracruz.tecnm.mx

Doctora en Ciencias Bioquímicas por el Instituto de Biotecnología de la unam. Cátedra-conacyT desde 2018, comisionada en el Instituto Tecnológico de Veracruz en la Unidad de Investigación y Desarrollo en Alimentos. Investigadora Nacional Nivel I. Profesora de Tiempo completo de 2008 a 2018 y Jefa de la División de Estudios de Posgrado de 2017 a 2018 en la Universidad del Papaloapan, perteneciente al Sistema Universidades del Estado de Oaxaca. Directora de tesis de licenciatura, maestría y doctorado. Actualmente su línea de investigación radica en la generación de herramientas biotecnológicas para el desarrollo y producción de biocombustibles de segunda generación.

\section{Maria Elena Ortiz-Soto elena.ortiz_soto@uni-wuerzburg.de}

Doctora en Ciencias Bioquímicas por el Instituto de Biotecnología de la unam. En el año 2011 obtuvo una beca del Servicio Alemán de Intercambio Académico (DAAD, por sus siglas en alemán) para realizar estudios posdoctorales en Alemania. Actualmente es investigadora en el Instituto de Química Orgánica de la Universidad de Würzburg. Pertenece al grupo de Química Orgánica y Biológica dirigido por el Dr. Jürgen Seibel. Su área de investigación incluye el estudio de glicosiltransferasas eucarióticas y bacterianas, implicadas en procesos patológicos, y la modificación por medios químicos y/o genéticos de glicósido hidrolasas bacterianas, de importancia en el área de alimentos. Ha supervisado proyectos financiados por la Comisión Europea, así como proyectos binacionales de vinculación entre científicos alemanes y mexicanos. 


\section{Introducción}

Si has leído el libro o visto la película El extraño caso del Dr. Jekylly Mr. Hyde, probablemente recuerdes el profundo conflicto entre el bien y el mal que atormentaba al Dr. Henry Jekyll y a su amigo Edward Hyde. Esta dualidad intrínseca entre conceptos opuestos es un elemento muy explotado en la literatura y en el cine. La sacarosa o azúcar de mesa, la glucosa y la fructosa serían este tipo de personajes en un bestseller con marcados claroscuros. Todos conocemos a estos protagonistasy, aunque a muchos les encantan y a más de uno le causan pesadillas, son absolutamente esenciales para el funcionamiento celular. Asimismo, hay otros azúcares no tan presentes en nuestras conversaciones que cumplen funciones menos evidentes, más allá de servir como

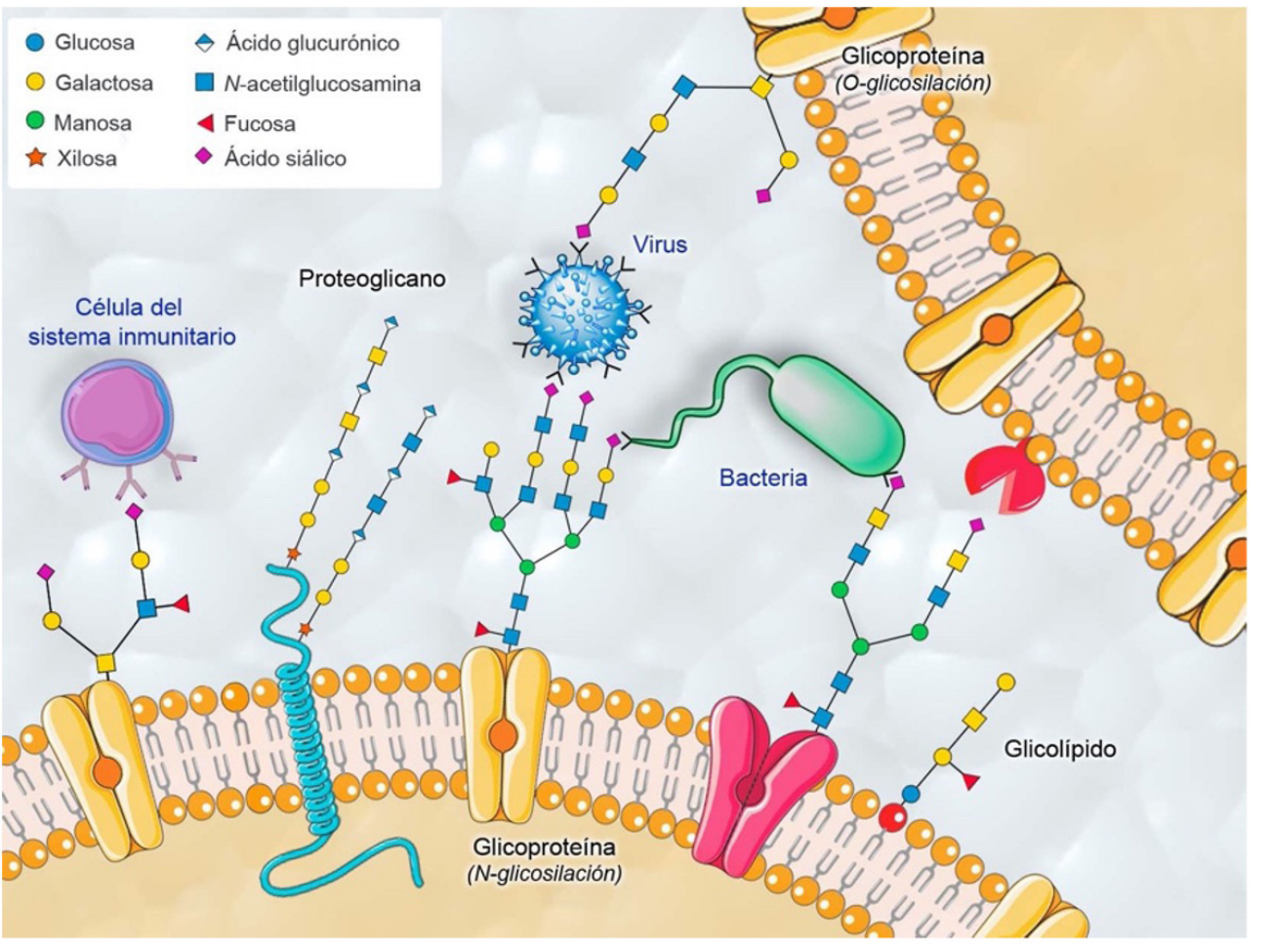
edulcorantes o como fuentes de energía, y que son parte de historias igual o más emocionantes. A continuación, revisaremos la importancia de los azúcares menos conocidos en eventos biológicos, como el reconocimiento celular, el establecimiento y progreso de infecciones microbianas, la activación de la respuesta inmune, y la comunicación microbiota-intestinocerebro.

\section{La personalidad múltiple de los azúcares}

Los azúcares son moléculas complejas en términos estructurales y químicos. Existen en forma de mono-, oligo- o polisacáridos, ${ }^{1}$ donde la configuración y la posición de su enlace con otros

Figura 1. Estructura y función de algunos azúcares que decoran la superficie celular. Elaboración: Maria Elena OrtizSoto; la figura incluye elementos de Smart servier medical art y de la plataforma GlycoGlyph.

${ }^{1}$ Los monosacáridos son los azúcares más sencillos, y consisten en una sola molécula de azúcar. Los oligosacáridos contienen de 2 a 12 monosacáridos, y los polisacáridos son moléculas formadas por la unión de más de 12 monosacáridos. azúcares es un factor más de diversificación. Al arreglo estructural de los azúcares que decoran proteínas y lípidos de la superficie celular se le denomina perfil o patrón de glicosilación, y está determinado por su origen celular.

El perfil de glicosilación de bacterias, levaduras y células de mamífero difiere en su complejidad estructural y en la variabilidad de los azúcares que lo componen. Los glicolípidos y las glicoproteínas - lípidos y proteínas unidos a cadenas de azúcaresse conocen colectivamente como glicoconjugados, y su patrón de glicosilación determina de forma muy específica algunos de los procesos fisiológicos o infecciosos en los que la célula participa (Schjoldager et al., 2020; Varki, 2017; ver figura 1). Se podría decir que en él radican las múltiples personalidades de los azúcares, aunque afortunadamente su estructura nos permite conocer, en muchos casos, cuál de ellas ha tomado el control. 


\section{Los azúcares como herramientas moleculares en infecciones microbianas}

¿Qué personaje de ficción viene a tu mente si hablamos de maestros del disfraz? Probablemente Sherlock Holmes, el hábil detective capaz de desenmascarar villanos haciéndose pasar en ocasiones por alguien diferente. Pero hasta el genio analítico de Sherlock podría ser superado si sus antagonistas se disfrazaran mejor que él, como Neisseria meningitidis o Trypanosoma cruzi. La primera es una bacteria que puede causar meningitis y sepsis con consecuencias fatales. T. cruzi es el parásito causante de la enfermedad de Chagas, un padecimiento endémico en varios estados de México. El arma secreta de ambos patógenos son los azúcares que cubren su superficie, con los que evaden las defensas del hospedero.

Entre los azúcares más comunes en la superficie celular de mamíferos se encuentran los ácidos siálicos (As), que funcionan como receptores para un gran número de funciones vitales y participan en procesos como la reproducción o el desarrollo y función neuronal (Schjoldager et al., 2020). Sin embargo, también son utilizados por virus, bacterias y parásitos para lograr el inicio y establecimiento de infecciones. Como toda una profesional de la imitación, $N$. meningitidis sintetiza y decora sus glicoconjugados con As. De esta forma, el sistema inmunitario de los mamíferos que infecta (el Sherlock en este ejemplo) no puede identificar al patógeno como un agente extraño, lo que contribuye a la supervivencia y virulencia de esta bacteria. En el mismo sentido, el parásito T. cruzi es también un maestro, pero del atraco. Como no es capaz de sintetizar sus propios as, los roba del hospedero (ver figura 2). Su estrategia para sobrevivir en la célula es usar armas enzimáticas muy potentes - las trans-sialidasas - , para unirse a los as del hospedero y transferirlos después hacia las mucinas que abundan en su superficie (da Fonseca et al., 2019). Las mucinas son proteínas hiperglicosiladas que protegen al parásito de cualquier ataque por parte del vector y del hospedero que infectan (ver figura 2).

Figura 2. Trypanosoma cruzi

"roba" moléculas de ácido siálico de los glicoconjugados del hospedero y los transfiere a las mucinas de su superficie. Elaboración: Maria Elena Ortiz-

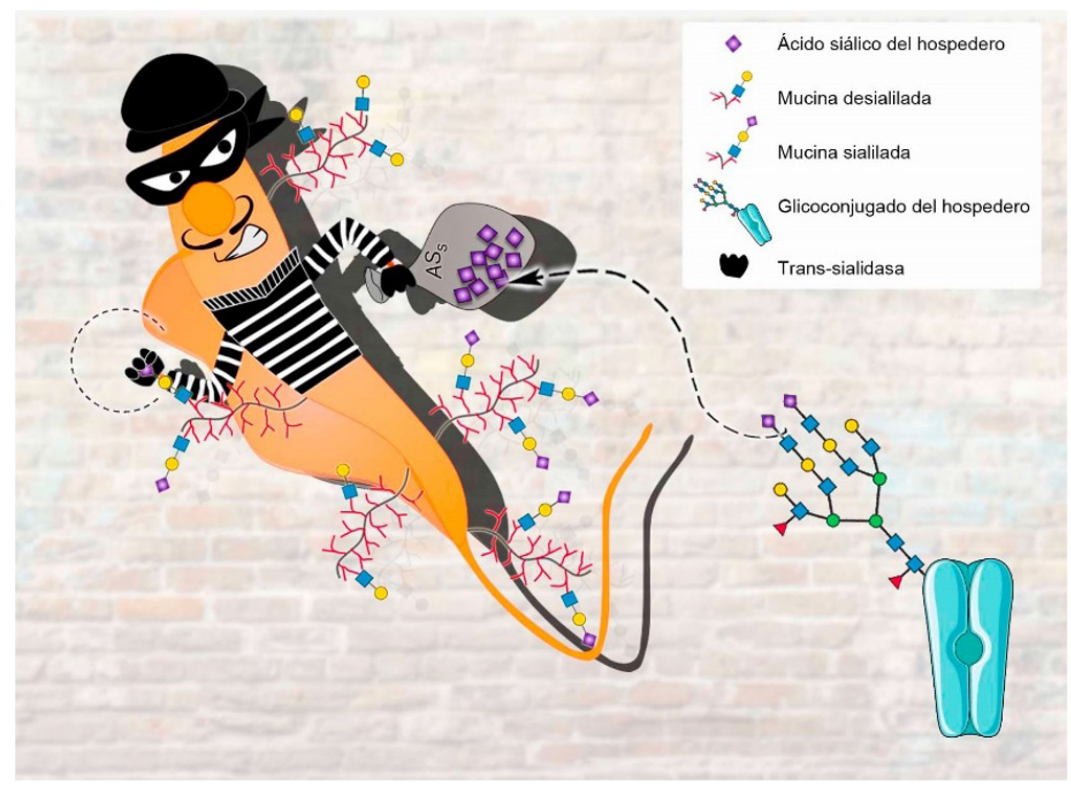


Otro elemento importante en el arsenal molecular de los microorganismos son las proteínas de unión a azúcares, que se localizan en su superficie celular o son parte de sus apéndices motores. Estas proteínas (lectinas) reconocen los azúcares del hospedero de forma sumamente específica, de manera que un patógeno sólo puede infectar el tipo de tejido que muestre determinado patrón de glicosilación, lo que se conoce como tropismo tisular. Bacterias patógenas comunes como estreptococos y estafilococos se unen a los as de los tejidos que colonizan, y pueden usarlos como fuente de carbono y nitrógeno. Los as también son los favoritos de Helicobacter pylori —una bacteria que está presente en 50\% de la población mundial y que puede ser causante de cáncer de estómago-, ya que le ayudan a unirse a la mucosa gástrica y la protegen de ser capturada y digerida por células del sistema inmunitario. (Poole et al., 2018).

¿Y los virus? ¿Qué sucede con los villanos de moda? Pues sí, adivinaste, ellos también despliegan proteínas o azúcares que permiten su anclaje al hospedero y les gusta modificar o camuflarse con azúcares. Los exhiben en las proteínas de la envoltura (membrana lipídica externa) o de la cápside (cubierta proteíca que protege al material genético) presente en algunos virus. Un ejemplo serían las glicoproteínas a manera de espículas (proteína S, de spike) que forman la corona del SARS-CoV-2, el terrible virus causante de la actual pandemia que, según la oms, hasta el momento ha provocado a nivel mundial más de 2 millones de muertes (WHO, 2021). La infección inicia cuando la proteína $S$ ayuda al virus a unirse a la enzima convertidora de angiotensina 2 (ACE2, por sus siglas en inglés), que se encuentra en varios tipos de células. Para complicar más las cosas, los azúcares de la proteína S ayudan a evadir al sistema inmunitario del hospedero, al formar alrededor del virus una especie de capa de invisibilidad que dificulta su detección (ver figura 3). En la búsqueda de medidas de prevención y terapia contra sARS-CoV-2, equipos multidisciplinarios de científicos buscan desenmascarar y exponer sus debilidades, así como descubrir en qué medida sus azúcares contribuyen a la infección.

Figura 3. Los azúcares que decoran la proteína $\mathrm{S}$ del virus SARS-CoV-2 dificultan su detección por el sistema inmunitario. Elaboración: Maria Elena Ortiz-Soto. La figura incluye algunos elementos de Smart servier medical art.

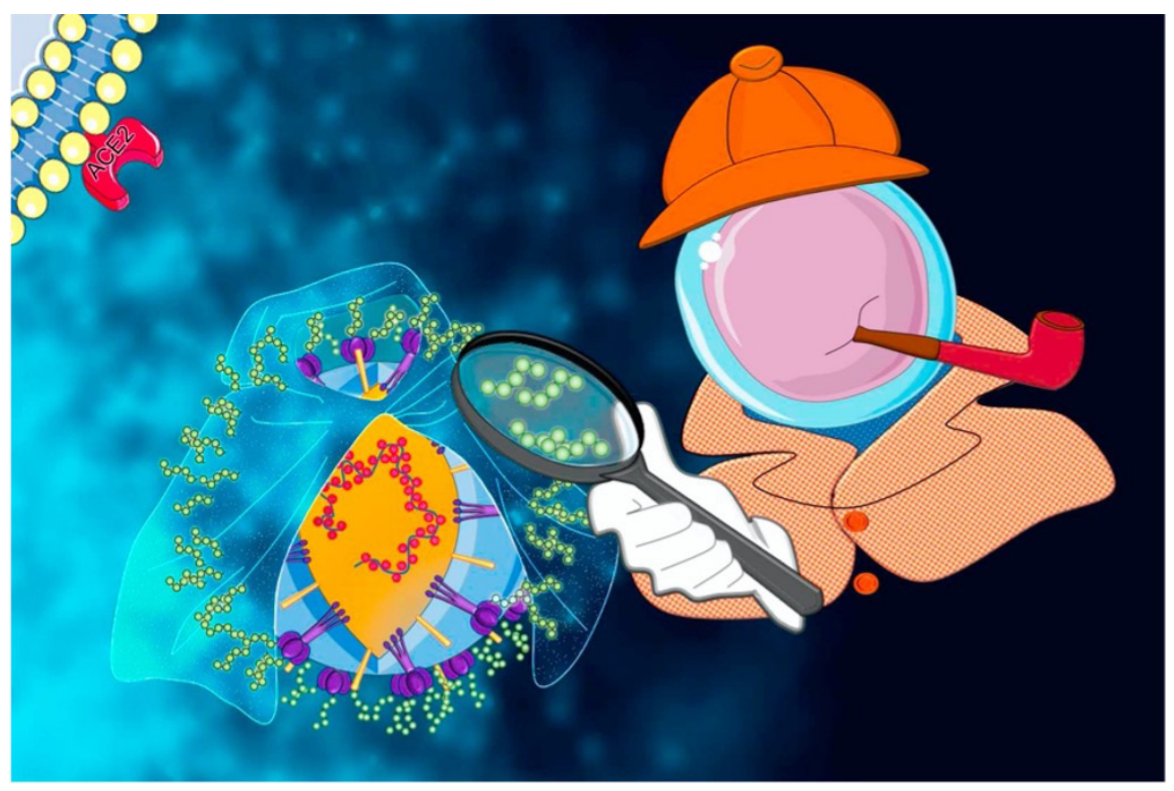


"¿Héroes o villanos? Azúcares en la salud y la enfermedad"

Ángela Ávila Fernández, Sandra del Moral y Maria Elena Ortiz-Soto

Vol. 22, Núm. 2, marzo-abril 2021

Revista Digital Universitaria

\section{Los azúcares como medio de reconocimiento y desarrollo de terapias}

¿Y qué pasa cuando tenemos al enemigo en casa? En algunas enfermedades crónicas autoinmunes, como la artritis reumatoide, algunos de nuestros anticuerpos, ${ }^{2}$ conocidos como IgG presentan una glicosilación incompleta, lo que prende la alarma del sistema inmunológico que "piensa" que hay un extraño en casa y moviliza un ataque en contra de sus propias células. Este "fuego amigo" permanente provoca graves daños a la salud; el Dr. Jekyll se transforma en el malvado Mr. Hyde, generando una terrible destrucción a su paso.

En este sentido, cambios mínimos como la presencia o eliminación de un azúcar externo pueden generar reacciones negativas en la respuesta inmune del paciente, como sucede en la incompatibilidad sanguínea, la cual está basada en la información que los eritrocitos ${ }^{3}$ presentan en su superficie. Los estudios del inmunólogo austriaco Karl Landsteiner dieron lugar, hace más de un siglo, a la clasificación de los cuatro grupos sanguíneos: A, B, AB y O.

En los eritrocitos con glicoconjugados del grupo A y B, los azúcares terminales corresponden a $\mathrm{N}$-acetilgalactosamina y galactosa, respectivamente. Las glicoconjugados del grupo AB contienen ambos azúcares terminales y en los del grupo $O$ ninguno de estos azúcares ocupa las posiciones más externas (ver figura 4). Si una transfusión sanguínea se hace con sangre no compatible, los anticuerpos presentes en el plasma identificarán a los glóbulos rojos transfundidos mediante sus azúcares superficiales y se encargarán de destruirlos, al considerarlos como agentes invasores.

Dado que la diferencia en los tipos sanguíneos se debe a sus azúcares externos, ¿habrá alguna manera de convertir células de un tipo sanguíneo en otro, para evitar la incompatibilidad? Un grupo de científicos canadienses modificó una galactosidasa de Streptococcus pneumoniae para poder eliminar la galactosa externa del tipo sanguíneo B y así convertirlo en el tipo O negativo, conocido también como tipo donante universal (ver figura 4; Kwan et al., 2015). El mismo grupo descubrió que Flavonifractor plautii, una bacteria anaerobia que forma parte de la microbiota intestinal, produce enzimas que pueden eliminar la N-acetilgalactosamina del tipo sanguíneo A (Rahfeld et al., 2019). Los estudios sobre el control del perfil de glicosilación tienen un gran alcance, no sólo para la conversión de sangre sino para el desarrollo de nuevas herramientas que contribuyan a evitar el rechazo en trasplantes de órganos (Rahfeld et al., 2019). La correcta glicosilación es tan importante que debe vigilarse de cerca en la producción de diversos tipos de péptidos y proteínas con actividad terapéutica (biofármacos), que se utilizan para contender con ciertas enfermedades crónicas y virales (Smith y Bertozzi, 2021). 
Figura 4. Conversión de los tipos sanguíneos A y B al grupo O mediante enzimas de F. plautil y S. pneumoniae. Elaboración: Sandra del Moral.
${ }^{4}$ Las bifidobacterias (llamadas así por su característica forma de Y) son bacterias que colonizan el tracto gastrointestinal. Las lactobacterias son bacterias productoras de ácido láctico, tienen forma de barra o bastoncillo y son parte de la microbiota del sistema digestivo y genital. Bifidobacterias y lactobacterias ejercen efectos positivos en la salud del hospedero por medio de su actividad metabólica y son las especies más comúnmente usadas como probióticos.

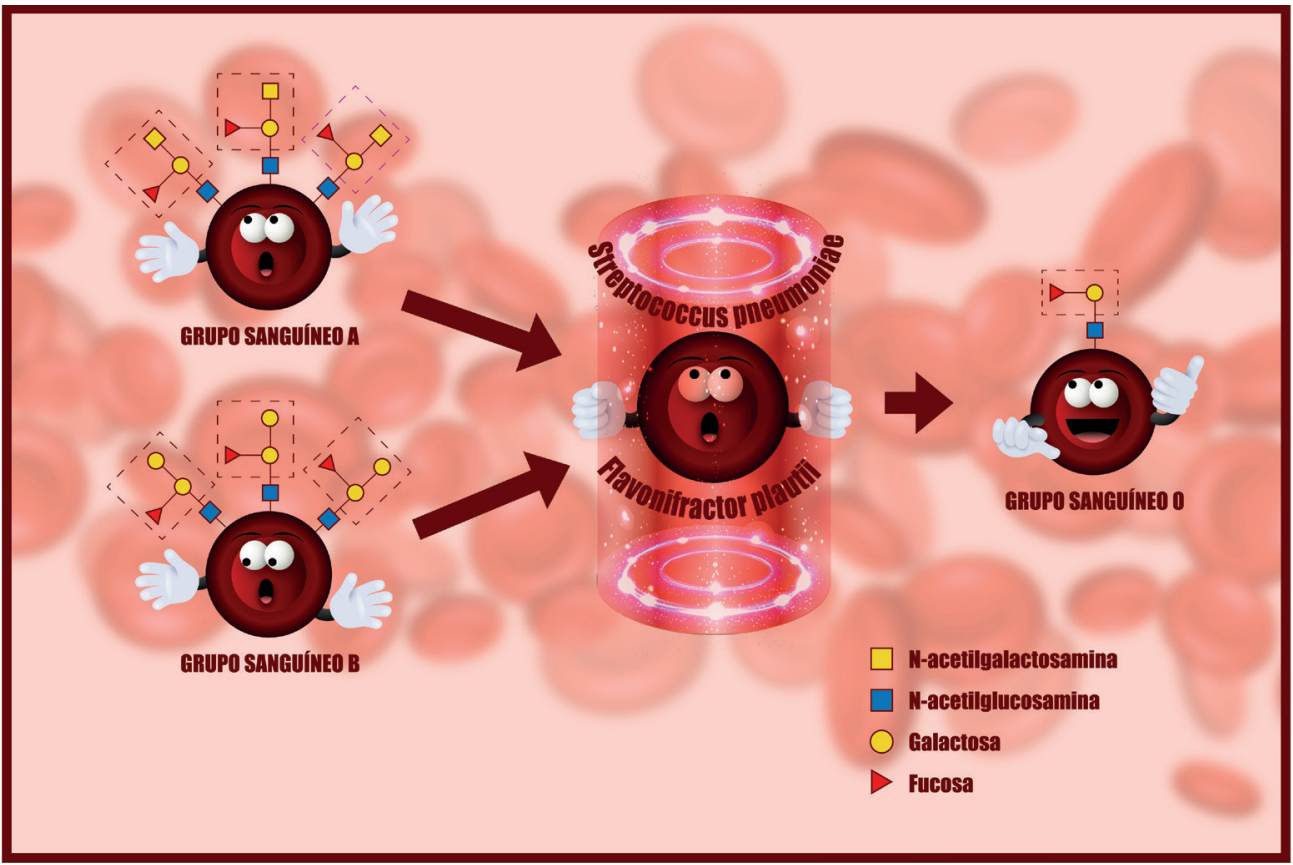

Los azúcares en la conexión microbiota-intestino-cerebro

A propósito de la microbiota intestinal, ¿qué pensarías si te dijera que algunos azúcares —cuál espinaca en la tira cómica de Popeye el marino- actúan dando fuerza a ciertas bacterias, que se convierten en verdaderos ejércitos en pro de la salud humana? Suena increíble, ¿no? Algunos polisacáridos pueden llegar al intestino grueso intactos y ahí ser metabolizados por la microbiota intestinal. El tipo de enlace que une sus monosacáridos no puede ser hidrolizado por la acidez del estómago o las enzimas de nuestro sistema digestivo, pero las enzimas de los microorganismos que habitan nuestro intestino grueso sí poseen las enzimas adecuadas para hacerlo. Estos azúcares, conocidos como prebióticos, se caracterizan por estimular en forma selectiva el crecimiento de las bacterias benéficas de nuestro intestino, entre ellas, las bifidobacterias y las lactobacterias. ${ }^{4}$

De esta forma, la ingesta de azúcares prebióticos trae como consecuencia un aumento en la población de bacterias benéficas que, como en un juego de estrategia, invaden el territorio y obligan al ejército de microorganismos patógenos, incluidos Clostridium y Klebsiella a replegarse. Algunos ejemplos de azúcares prebióticos son los polímeros de fructosa, como inulina y fructooligosacáridos, y los polímeros de glucosa no digeribles por el humano, conocidos como almidón resistente.

Como habrás notado, la glucosa y fructosa - el dolor de cabeza de muchos a la hora de contar calorías - pueden adoptar formas complejas que les confieren una personalidad completamente diferente y bajo estas formas actúan para nuestro beneficio. Los prebióticos se encuentran en diferentes fuentes vegetales, por lo que una dieta adecuada puede provocar cambios en 
la composición de nuestra microbiota intestinal y promover un buen estado de salud. Cuando el equilibrio de la microbiota se rompe, se genera una condición llamada disbiosis, en la que proliferan microorganismos patógenos y se desencadenan trastornos importantes a la salud. Esta disbiosis ha sido asociada con diversas patologías como alergias, trastornos intestinales inflamatorios y funcionales y comorbilidades psiquiátricas (Bercik et al., 2011).

Y a todo esto, ¿como hace la microbiota intestinal para ayudarnos o perjudicarnos? Pues, cual novela gótica, detrás de esta relación microorganismohumano se oculta un secreto que los científicos empiezan a develar. La microbiota intestinal, como voces interiores hablándonos al oído, envía mensajes en forma de compuestos químicos a nuestro cerebro y de esta forma manipula nuestro funcionamiento y comportamiento (ver figura 5). Esta comunicación entre la microbiota y el cerebro se realiza por dos vías. En la primera, la microbiota libera ciertos compuestos químicos que llegan al cerebro por medio de la sangre. En la segunda, otros compuestos químicos activan las terminales nerviosas en la mucosa intestinal y llevan información al cerebro a través del nervio vago.

Figura 5. La comunicación entre los microorganismos y el ser humano influye en su estado de salud. Elaboración: Ángela Ávila Fernández.

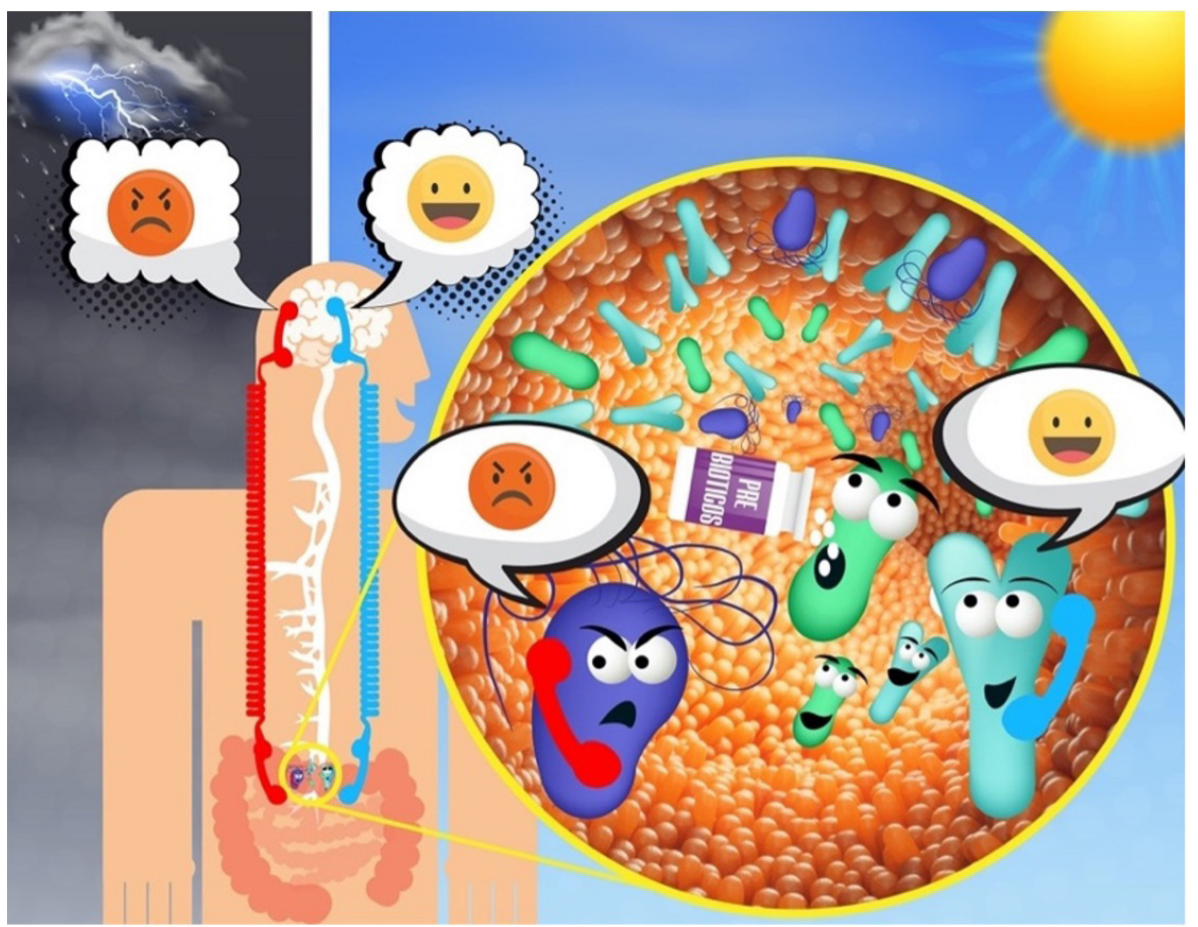

Por ambas vías de modulación de la función cerebral, se provocan cambios que afectan todo el cuerpo y que influyen en aspectos sociales de nuestra personalidad. Por ejemplo, cuando la población de microorganismos patógenos aumenta, el mensaje que se envía al cerebro es negativo y se manifiestan afectaciones a nivel de sistema digestivo y problemas de sistema nervioso, como ansiedad, depresión y mala memoria, lo que evidencia el lado oscuro de la relación microorganismo-humano. Además, una microbiota sana ha sido 
"¿Héroes o villanos? Azúcares en la salud y la enfermedad" Ángela Ávila Fernández, Sandra del Moral y Maria Elena Ortiz-Soto

Vol. 22, Núm. 2, marzo-abril 2021

Revista Digital Universitaria

asociada con una mejor memoria y aprendizaje y, debido a que parece haber una relación bidireccional entre la neuroinflamación y la depresión, el incremento de probióticos se asocia con efectos antidepresivos (Valles-Colomer et al., 2019).

Así, la microbiota intestinal provoca que el ser humano viva en el continuo e inherente conflicto entre salud y enfermedad, de la misma forma que el Dr. Jekyll y Mr. Hyde se debaten entre el bien y el mal. Y uno de los ingredientes de la poción mágica que contribuye a transmutarnos de un estado a otro es, sin duda, una alimentación provista de azúcares prebióticos. Entonces, la próxima vez que el comportamiento errático de algún amigo te sorprenda, esboza una sonrisa compasiva mientras piensas: ¡no eres tú, son tus microorganismos!

\section{Conclusiones}

¿Héroes o villanos? Aunque son elementos atractivos para amenizar historias, en sentido estricto, los azúcares no poseen atributos de maldad o de bondad, ya que sólo cumplen funciones biológicas seleccionadas a través de muchos años de evolución. Al igual que sucede con el material genético, la glicosilación es la forma de la célula de generar diversidad estructural y funcional a partir de un conjunto limitado de monómeros. Los azúcares están presentes en todo tipo de células y son en gran medida responsables del reconocimiento molecular, por lo que cumplen funciones variadas que no siempre nos benefician. Al tiempo que dirigen el control de calidad de glicoproteínas, actúan como reguladores inmunológicos y garantizan la integridad celular, también funcionan como puerta de entrada para patógenos y son marcadores moleculares en enfermedades autoinmunes o en diferentes tipos de cáncer. En estos y en muchos otros procesos que por falta de espacio no pudieron ser revisados en este artículo, los azúcares tienen un papel protagónico, pero esas son historias para otra ocasión.

\section{Referencias}

* Bercik, P., Denou, E., Collins, J., Jackson, W., Lu, J., Jury, J., Deng, Y., Blennerhassett, P., Macri, J., McCoy, K. D., Verdu, E. F., y Collins, S. M. (2011). The intestinal microbiota affect central levels of brain-derived neurotropic factor and behavior in mice. Gastroenterology, 141(2), 599-609, 609 e591-593. Dol: https://doi.org/10.1053/j. gastro.2011.04.052

* da Fonseca, L. M., da Costa, K. M., Chaves, V. S., Freire-de-Lima, C. G., Morrot, A., Mendonca-Previato, L., Previato, J. O. y Freire-de-Lima, L. (2019). Theft and Reception of Host Cell's Sialic Acid: Dynamics of Trypanosoma Cruzi Transsialidases and Mucin-Like Molecules on Chagas' Disease Immunomodulation. Front Immunol, 10, 164. Dol: https://doi.org/10.3389/fimmu.2019.00164

* Kwan, D. H., Constantinescu, I., Chapanian, R., Higgins, M. A., Kotzler, M. P., Samain, E., Boraston, A. B., Kizhakkedathu, J. N. y Withers, S. G. (2015). Toward Efficient Enzymes for the Generation of Universal Blood through Structure-Guided Directed Evolution. J Am Chem Soc, 137(17), 5695-5705. Dol: https://doi.org/10.1021/ ja5116088 
* Poole, J., Day, C. J., von Itzstein, M., Paton, J. C. y Jennings, M. P. (2018). Glycointeractions in bacterial pathogenesis. Nat Rev Microbiol, 16(7), 440-452. Dol: https://doi.org/10.1038/s41579-018-0007-2

* Rahfeld, P., Sim, L., Moon, H., Constantinescu, I., Morgan-Lang, C., Hallam, S. J., Kizhakkedathu, J. N. y Withers, S. G. (2019). An enzymatic pathway in the human gut microbiome that converts A to universal O type blood. Nat Microbiol, 4(9), 1475-1485. Dol: https://doi.org/10.1038/s41564-019-0469-7

* Schjoldager, K. T., Narimatsu, Y., Joshi, H. J. y Clausen, H. (2020). Global view of human protein glycosylation pathways and functions. Nat Rev Mol Cell Biol, 21(12), 729-749. Dol: https://doi.org/10.1038/s41580-020-00294-x

Smith, B. A. H. y Bertozzi, C. R. (2021). The clinical impact of glycobiology: targeting selectins, Siglecs and mammalian glycans. Nat Rev Drug Discov. Dol: https://doi. org/10.1038/s41573-020-00093-1

* Valles-Colomer, M., Falony, G., Darzi, Y., Tigchelaar, E. F., Wang, J., Tito, R. Y., Schiweck, C., Kurilshikov, A., Joossens, M., Wijmenga, C., Claes, S., Van Oudenhove, L., Zhernakova, A., Vieira-Silva, S. y Raes, J. (2019). The neuroactive potential of the human gut microbiota in quality of life and depression. Nat Microbiol, 4(4), 623632. Dol: https://doi.org/10.1038/s41564-018-0337-x

* Varki, A. (2017). Biological roles of glycans. Glycobiology, 27(1), 3-49. Dol: https:// doi.org/10.1093/glycob/cww086

wHO. (2021, 17 de febrero). wHo Coronavirus Disease (covid-19) Dashboard. https:// covid19.who.int/

\section{Cómo CITAR ESTE ARTículo}

* Ávila Fernández, Ángela, del Moral, Sandra y Ortiz-Soto, Maria Elena. (2021, marzo-abril). ¿Héroes o villanos? Azúcares en la salud y la enfermedad. Revista Digital Universitaria (RDU), 22(2). Dol: http://doi.org/10.22201/ cuaieed.16076079e.2021.22.2.5 